\title{
The Impacts of Incentives for International Publications on Research Cultures in Chinese Humanities and Social Sciences
}

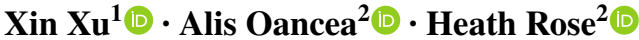

Accepted: 7 March 2021 / Published online: 6 April 2021

(C) The Author(s) 2021

\begin{abstract}
Incentives for improving research productivity at universities prevail in global academia. However, the rationale, methodology, and impact of such incentives and consequent evaluation regimes are in need of scrutinization. This paper explores the influences of financial and career-related publishing incentive schemes on research cultures. It draws on an analysis of 75 interviews with academics, senior university administrators, and journal editors from China, a country that has seen widespread reliance on international publication counts in research evaluation and reward systems. The study focuses on humanities and social sciences (HSS) as disciplinary sites, which embody distinct characteristics and have experienced the introduction of incentive schemes in China since the early 2000s. Findings reveal tensions between internationalization and indigenization, quality and quantity, integrity and instrumentalism, equity and inequity in Chinese academia. In particular, we argue that a blanket incentive scheme could reinforce a managerial culture in higher education, encourage performative objectification of academics, and jeopardize their agency. We thereby challenge 'one-size-fits-all' policymaking, and suggest instead that institutions should have the opportunity to adopt an ethical and 'human-oriented' approach when developing their research incentives and evaluation mechanisms.
\end{abstract}

Keywords Humanities and social sciences $\cdot$ International publications $\cdot$ Research culture $\cdot$ Academic incentive schemes $\cdot$ Research productivity $\cdot$ Chinese higher education

$\mathrm{Xin} \mathrm{Xu}$

xin.xu@education.ox.ac.uk

1 Centre for Global Higher Education, Department of Education, University of Oxford, Oxford, UK

2 Department of Education, University of Oxford, Oxford, UK 


\section{Introduction}

Efforts to incentivize research productivity, and particularly the volume of international publications, have become a feature of knowledge generation in many university cultures (Franzoni et al. 2011). This emphasis on publishing internationally is framed normatively, in terms of relative standards of perceived academic quality and impact. It is often premised on expectations of a link from financial or career-related rewards or constraints, to increases in the volume of (high-quality) publications, and to wider academic, cultural, and societal benefits. However, these assumptions may not always hold in different (multi)disciplinary and institutional contexts.

This paper explores and problematizes the complexities around using incentives to stimulate changes in research cultures and academic behaviours, which intend to boost the volume of international publications. The paper reports insights from a study of incentives for international publications in Chinese humanities and social sciences (HSS), conducted between 2015 and 2018 (Xu 2019). In this paper, we focus on the following question:

How have incentives for international publications influenced research cultures of Chinese Humanities and Social Sciences?

\section{Internationalization of HSS and Incentives for International Publications}

The internationalization of higher education and research has been a pivotal policy concern in contemporary China, particularly since the reforms of 1978 (Yang 2014). The initial focus was on natural sciences (NS), where incentives for publications in Science Citation Index (SCI) journals appeared as early as in the 1980s (Qin and Zhang 2008). The volume of science publications by Chinese scholars has grown tremendously over the past decades. To date, China has a $21 \%$ share of global science publications, ranking first as a single country in the world (US National Science Foundation 2020).

The volume of Chinese HSS international publications remains much smaller in comparison (US National Science Foundation 2020), and the development of HSS was initially 'overlooked' in national policies (National Education Committee 1994). Since the early 2000s, HSS began to garner growing policy attention in China, as its internationalization approach shifted from unidirectional aims of 'learning from advanced research in global academia' to reciprocally 'going-out' and enhancing global 'discourse power' (National Education Committee 1994; Ministry of Education 2011a). The degree of internationalization is often benchmarked with evaluative tools like university rankings, which rely heavily on publication metrics (Hazelkorn 2011).

Under both policy orientation and performative pressures like rankings, an increasing number of Chinese universities started to incentivize HSS international outputs (Dang 2005; Zhu 2009). Such incentive schemes prevail among 
Chinese universities, particularly those in the 'Project 985' and 'Project 211' programs. An examination of 172 incentive documents collected at 116 ' 985 ' and '211' universities found that by 2016,84 out of the 116 had set up formal university-level incentive schemes for HSS international publications (Xu et al. 2019). Most schemes are monetary or career-related incentives, that recognized journals indexed by the Social Sciences Citation Index (SSCI) and the Arts and Humanities Citation Index (A\&HCI) as 'HSS international journals', and granted them with larger financial bonuses or higher weights in career development than most domestic publications (Xu et al. 2019).

The ' 985 ' and ' 211 ' projects were key national projects initiated in the 1990s to improve the research capacity of selected top Chinese universities (China Academic Degrees \& Graduate Education Information 2009; China Academic Degrees \& Graduate Education Information 2012). In the late 2010s, 'Project 985' and 'Project 211' were replaced by the 'Double First-Class Programme' to build 'double first-class universities' and 'double first-class disciplines' (Ministry of Education et al. 2017). All '985' and '211' universities remained in the 'Double First-Class Programme', while 25 non-985/211 universities entered the new initiative (Ministry of Education et al. 2017).

Bibliometric studies suggest that one outcome of both policy emphasis and institutional incentives has been a growth of SSCI and A\&HCI publications by Chinese academics (Liu et al. 2015). Some scholars perceived the growth as a manifestation of the increasing global visibility of Chinese research (e.g. Jiang 2017). In this interpretation, publication incentives are seen as a timely and effective means to address the risk of marginalization of Chinese research and knowledge.

Some scholars expressed concerns over a potential predicament of 'self-colonization' (Dang 2005: 68) - due to the over-emphasis on international publications, Chinese HSS academics may 'accept Western concepts and theoretical frameworks without critical scrutiny and creative thinking' (Deng 2010: 182), and focus more on Western issues or selectively on Chinese issues of interest to Western countries (Zhu 2009). Chinese central government shared a similarly cautious tone. Over the past decade, the government has issued a series of policies, urging universities and academics to respect both national and international research, avoid the tendency to emphasise quantity over quality, make rational use of citation indices like SCI, SSCI, A\&HCI, and CSSCI (Chinese Social Sciences Citation Index), and recognize the distinctiveness of each discipline and various types of research achievements (Ministry of Education 2011b; General Office of the CCP Central Committee and General Office of the State Council 2018; Ministry of Education and Ministry of Science and Technology 2020). Particularly, several policies issued by the central government in 2020 emphasised the importance of publications in domestic journals, and advocated against using SSCI- or SCI-related metrics as the direct basis for research evaluations (Ministry of Education 2020; Ministry of Education and Ministry of Science and Technology 2020; Ministry of Science and Technology 2020). 


\section{Publication Metrics as a Proxy of Research Internationalization}

The notion of international research and the indicators by which to judge it are shaped not only by national policy but also by institutional and disciplinary cultures. Numerous institutions worldwide have used counts of papers and impact factor as monitoring tools for research performance, largely on grounds of convenience and apparent objectivity, which has triggered scholarly and public controversy (e.g. Butler 2003; Chou 2014). Notably, there has been push-back from scholarly communities worldwide against the indiscriminate use of journal-based metrics (such as impact factors) as a proxy of research quality, see for instance the San Francisco Declaration on Research Assessment (DORA) (American Society for Cell Biology 2012).

Language-wise, the concept of 'international publications' is interpreted in many countries as English language publications (Lillis and Curry 2010), or simply as SCI, SSCI, and A\&HCI publications, as is the case in China (Xu 2020a). This is despite the widely acknowledged linguistic, geographical, disciplinary, epistemological, and ideological limitations or bias of those databases (Klein and Chiang 2004; Archambault et al. 2006; Mongeon and Paul-Hus 2016). For instance, 88\% SSCI journals are published in English, the four China-based journals are English-medium, and there is no Chinese-medium SSCI journal (Web of Science Group 2020). Thus, when SSCI journals are equated to 'international journals', as Lillis and Curry (2010) noted, 'international' becomes almost synonymous with 'Anglophone'.

Disciplinary cultures further influence both the quality and significance of publication and citation data, and their relevance for use in evaluation contexts. As research governance policies for HSS often follow suit with those for NS (Donovan 2005), scholars have cautioned against simply borrowing evaluation methodologies from NS to HSS, which may place significant weight on bibliometric data (Nederhof 2006; Hsuan and Chang 2008; Qin and Zhang 2008). Scholars argued that HSS research differs from NS research, in terms of local or international orientation, epistemic characteristics, the level of English language dominance, and the most common outcome types (Nederhof 2006; Reale et al. 2018).

In response, suggestions (some of which were directly relevant to the Chinese context) to improve the use of bibliometric indicators in HSS research assessment have included proposals for alternative databases that may be more comprehensive (Hicks and Wang 2010); for field-normalization of citation metrics (Moed 2010; Li et al. 2013; Waltman et al. 2013); or for combinations of citation metrics with other evaluation methods, such as informed peer review (Garfield 2003) or expert review (Franceschet and Costantini 2011).

\section{Managerial Culture and Performative Accountability}

Recent models of research governance have changed how institutions frame academic work, academic performance, and the relationship between the different constituent parts of the university and the relationship to society and industry (Deem et al. 2007; Fanghanel 2011). The use of metrics and quantifiable targets 
of performance is at the heart of that change, which was summarized critically by Kelly and Burrows (2012: 130) as the 'performative co-construction of academic life through myriad metrics'.

Managerialism and the associated performative accountability regimes have had impact at the macro-level on policies and systems, and at the meso- and micro-levels of basic units and individuals (Henkel 2005; Scott 2006). Research on academics under managerialism (characterized by ideologies and practices of competition, control and hierarchical accountability) has identified influences on academics' identity and autonomy, and on quality assurance in teaching and research (e.g. Montgomery 2011; Lucas 2006; Kolsaker 2008; Slaughter and Leslie 1997; Trow 1994). Academics may face intense institutional pressures on individual research horizons (Fanghanel 2011), and as Blackmore (2003: 5) puts it, 'the management of knowledge production and dissemination has become the core work of universities, repositioning academics as managed professionals'.

Arguably, the publication incentive mechanism in China is symptomatic of a managerial culture, where universities use incentives to translate their performative pressures into academics' accountability (Xu 2020b). Nonetheless, the picture of academic autonomy in Chinese academia differs from that in the West, especially in the HSS (Gao and Zheng 2018). Chinese academics live in a paradoxical situation in which they strive for autonomy while aligning their academic pursuits with national interests (Zha and Shen 2018), which are underpinned by publishing incentives. This delicate situation is ripe for an investigation into how such incentives affect the research cultures in which academics operate.

\section{Methodology}

This study draws on 75 interviews with 65 HSS academics and six senior university administrators from six Chinese universities, and four Chinese HSS journal editors. The six case universities were selected from the 116 ' 985 ' and ' 211 ' universities, with consideration of their geographical locations, research capacity, and distinct characteristics. Three were formerly ' 985 ' universities and three ' 211 ' universities, and three HSS-oriented universities and three NS-oriented universities. All three '985' universities are also 'double first-class universities', and all three '211' universities have 'double first-class disciplines'. The universities are located in northern China (identified as Uni-NA and Uni-NB), eastern China (Uni-EA and Uni-EB), western China (Uni-W), and central China (Uni-C).

HSS academic interviewees were selected through a purposive, criterion-based sampling strategy, aiming for variation and balance along the following criteria: institutional affiliation, discipline, employment function, career stage, and publication record. Nine interviewees were from Uni-NA, seven from Uni-NB, 11 from Uni-EA, 13 from Uni-EB, ten from Uni-W, and 15 from Uni-C. 27 academics were from the Humanities, and 38 from Social Sciences. 15 were assistant professors, 29 were associate professors, and 21 were professors. 31 had overseas educational backgrounds, and other 26 had overseas academic visiting experiences. 41 had international publications. Four of them served as part-time editors 
for English journals, and six held departmental senior administrative roles. Interviewees also included four Chinese journal editors from an SSCI journal, an A\&HCI journal, and two CSSCI journals, as well as six senior administrators (SA) who had participated in creating university-level incentive policies.

The interviews were conducted during September to October 2016 and February to May 2017 by one author in Mandarin Chinese. Ethical clearance was obtained from the authors' university research ethics committee. 71 interviews were audio-recorded; note-taking was used for the other four, all upon participants' consent.

Interview data were coded through three rounds of coding, starting with data immersion and open coding. This process generated a rich set of basic, closeto-text codes, and was followed by pattern coding to develop themes and categories (Saldaña 2013). Table 1 displays an example of codes and themes. Techniques of clustering, comparing, contrasting, and building logical connections between codes (Rietjens 2015) were used to generate, in the final stage of coding, the themes around which the remainder of this paper is structured. Table 1 shows some examples of the codes. At each stage of coding, qualitative reliability checks took place with assistance from the co-authors.

This paper quotes English phrases and Chinese phrases/sentences used by interviewees that are important. English phrases are quoted in italics. Chinese phrases/sentences are either translated or cited in the pinyin form, supplemented with Chinese characters and English translations. Back-translation of interview quotes has been conducted to minimize the risk of misrepresentation of participants' views.

\section{Findings: 'Opening Pandora's Box'? Rising Tensions in Research Cultures}

The findings revealed widespread awareness of the incentives for HSS international publications, coupled with serious concerns about the potential undesirable influences on research values, norms, and standards. One academic interviewed was worried that incentive schemes might 'open Pandora's box', bringing undesirable harm to Chinese HSS academia. Many of the findings presented in this section resonate with this point of view.

Participants used some common language to describe the influences of the schemes. For example, six academics and one senior administrator commented that incentive schemes were like 'the conductor's batons' (zhi hui bang 指挥棒), guiding and influencing all academics. Five interviewees maintained that incentives and the attached values would shape the 'ecology of academia' in various ways. Participants argued that incentive schemes had challenged or reinforced certain internal and external conflicts in the research culture, particularly perceived between internationalization and indigenization, quality and quantification, integrity and instrumentalism, equity and inequity. Each of these major themes is explored further in this section of the findings. 
Table 1. Examples of codes

\begin{tabular}{|c|c|c|c|}
\hline Interview excerpts & Open coding & Pattern coding & Themes \\
\hline $\begin{array}{l}\text { "The recently reformed incen- } \\
\text { tive policy is, as we tu bie see } \\
\text { it, very striking. Returnees } \\
\text {... are bringing us huge } \\
\text { impacts." } \\
\text { [Academic-C12] }\end{array}$ & $\begin{array}{l}\text { Incentive scheme's influences } \\
\text { on non-returnees } \\
\text { Returnees' impacts on non- } \\
\text { returnees under the incentive } \\
\text { scheme } \\
\text { 'Tu bie' }\end{array}$ & $\begin{array}{l}\text { Inequity: returnees ver- } \\
\text { sus non-returnees }\end{array}$ & $\begin{array}{l}\text { Equity and } \\
\text { Inequity }\end{array}$ \\
\hline $\begin{array}{l}\text { "It (Publishing internationally) } \\
\text { will take me lots of time, as I } \\
\text { am not hai gui like some oth- } \\
\text { ers are. Since the beginning } \\
\text { of my academic training, } \\
\text { the training has not been in } \\
\text { English." } \\
\text { [Academic-EA8] }\end{array}$ & $\begin{array}{l}\text { Incentive scheme's influences } \\
\text { on non-returnees } \\
\text { Returnees' advantages in inter- } \\
\text { national publications (with } \\
\text { training in academic English } \\
\text { writing) } \\
\text { 'Hai gui' }\end{array}$ & $\begin{array}{l}\text { Inequity: returnees ver- } \\
\text { sus non-returnees }\end{array}$ & $\begin{array}{l}\text { Equity and } \\
\text { Inequity }\end{array}$ \\
\hline $\begin{array}{l}\text { "Foreign universities empha- } \\
\text { size on research methodolo- } \\
\text { gies training, so almost all } \\
\text { those coming back from } \\
\text { overseas can publish in some } \\
\text { core international journals." } \\
\text { [Academic-W10] }\end{array}$ & $\begin{array}{l}\text { Returnees' advantages in } \\
\text { international publications } \\
\text { (with training in research } \\
\text { methodology) }\end{array}$ & $\begin{array}{l}\text { Inequity: returnees ver- } \\
\text { sus non-returnees }\end{array}$ & $\begin{array}{l}\text { Equity and } \\
\text { Inequity }\end{array}$ \\
\hline
\end{tabular}

\section{Internationalization and Indigenization}

The interviews demonstrated a prevailing awareness of internationalization in Chinese higher education, as 45 of the participants talked about 'internationalization', including one journal editor, two senior administrators, and 42 academics. Many participants recognized internationalization as a strategic goal of their institutions, manifested in various guises, such as encouraging international publications, recruiting returnees or foreign faculty members, establishing crossinstitutional cooperation for overseas student exchanges or academic visits, and requiring the internationalization of teaching and curriculum. Participants noted that academics engaged in international research activities would generally be better positioned to publish internationally:

In our department, academics who can publish internationally are those who had received education abroad, served as post-doctoral researchers overseas, conducted academic visits at foreign institutions, or collaborated with foreign academics. Only through such processes, will they gradually become familiar with it. Academics who had international publications like me all shared similar experiences. (Academic-W10)

Most academics interviewed perceived the incentives for international publications as 'an institutional signal' (Academic-C8) or a 'lever' for internationalization (Academic-EA8), to 'guide and motivate' academics to become internationalized (Academic-C8). Some academics deemed the trend of internationalization as 'essential' or 'inevitable' to the development of their discipline or institution 
(e.g. Academic-EA3, C8, W10), and they reported a supportive or compliant attitude: 'Since it is inevitable, what we can do is to adapt to it' (Academic-C12). International publications, under such circumstances, were treated as 'carriers' or 'instruments' for internationalization:

For internationalization or international communications, international publications might be very important carriers or instruments. ... Once published, papers will stay there forever. For people conducting research on the same topic around the world, if you publish in English, they will learn about you; but if you publish in Chinese, communications would normally be restrained to domestic academia. There might be exceptions for some China-related topics or some particularly good papers, which might be studied by some foreign academics researching China. (Academic-NA3)

However, some interviewees argued for the indigenization of Chinese HSS, as they observed domestic research being treated as inferior to international research under the incentive schemes. They proposed that internationalization agendas should move from a 'superficial level' (Academic-C1) of simply 'chanting slogans' (han kou hao, 喊口号) (Academic-C9), to a more balanced, substantial, and confident approach. Academic-EB4 noted that the university's over-emphasis on internationalization reflected a lack of confidence in domestic research. Similarly, Academic-W2 commented that:

Most Chinese universities now lack confidence, relying on others' standards for evaluation. But in the future, I believe we will have more self-confidence, thinking we are doing excellent research, and we do not need to borrow external standards for assessments.

'Going out' and 'discourse power', the two terms highlighted in Chinese national policies for internationalization, appeared in interviews with 14 academics, two senior administrators, and one journal editor. Most mentions were aligned with government policies to encourage the strengthening of Chinese voices in international academia, particularly by harnessing the unique empirical and theoretical contributions of Chinese HSS:

If you think about our Social Sciences research, ever since the 1500s, the terms, concepts, or the whole discourse system were shaped by Western research. We failed to find and showcase our uniqueness to interpret Chinese experiences or evidence. Now we are just borrowing Western theories to interpret some facts in China, rather than using our cases to develop theories further. (Academic-NB5)

Some participants shared similar opinions, arguing that Chinese academics should 'go out' to 'introduce more Chinese research to the world and deepen discussions with each other' (SA-EA). Academic-W4 argued that internationalization is for reciprocal communications rather than one-sided 'learning from them', and that promoting Chinese research to the world reflected an improved level of self-confidence: 'Promulgating and spreading the civilization means we are confident'. 


\section{Quality and Quantity}

Although a few academics and senior administrators considered incentives as focusing more on quality than quantity, 26 interviewees commented on 'quantitative evaluation'. They referred to 'quantity' as the number of publications, the impact factors, or citations counts, which were used in incentive policies and evaluation regulations. For instance, Academic-EA1 remarked: 'We (the university) only look at numbers. How many so-called SSCI papers you have published - this is something countable.' Academic-W8 also pointed out: 'Although we emphasize quality, you have to meet the quantitative thresholds first, since they will first count how many publications you have'.

Some academics criticized the quantitative evaluation culture, arguing that it 'corresponds to the bureaucratic and administrative culture in higher education' (Academic-EB9) and 'will ruin academic research' (Academic-EA5). AcademicEB4 underlined that since it was no longer difficult for most of his colleagues to publish internationally, the real priorities should be research quality and impact: 'We should see whether those publications have real influences and are genuinely good articles'. Academic-NB1 had recently failed in a promotion assessment, and argued that the incentives for international publications would lead to an evaluation environment where only numbers mattered:

Everyone will focus on papers, the more, the merrier; English is better than others. ... They do not look at results, regardless of what is being published, what is the contribution to society, whether it is innovative or not. This is the impression my department has left me, because they told me this is the case, that I did not have an adequate number of publications.

Academic-W4 reflected that it remained difficult to assess individuals based on quantitative measures and without the 'reification' (wu hua, 物化) of them. He explained that through 'reification', which is the treatment and alienation (yi hua, 异化) of people as things (Lukács 1971), academics are not assessed as individual human beings, but as performative entities represented and reflected by external characteristics like the number of publications. A quote by Academic-EB8 illustrates the pitfall of reification: 'One must become a hen to lay eggs for us (for the institution). Everyone is a clucking hen, laying eggs for us every day'.

Academic-EB8 suggested that academics' professional life should be assessed as a holistic entity comprising teaching, publications, moral standards, and social responsibility. However, he thought the current 'Academic GDP-ism' (xueshu GDP zhuyi, 学术 GDP 主义), which mainly focuses on numbers, would shrink all aspects of academic life to one dimension, that is publications. Similarly, some academics expressed concerns that teaching could be 'devalued' (AcademicWH11), since teaching weighed less than publications in incentives and evaluations - 'as important as it is, teaching appears inferior to research' (AcademicW4). Participants noted that incentive schemes had resulted in some 'academic celebrities' (Academic-WH11) who 'prioritized publications' (Academic-SHB8) and 'sacrificed the needs of students' (Academic-WH11). 
Meanwhile, some interviewees noted the benefits of quantification in research evaluation, while acknowledging its limitations. A comment by Academic-EB1 captures this mixed attitude. He remarked that indicators and rankings were like 'distorting mirrors' (ha ha jing, 哈哈镜) in amusement parks, which can tell people something but not everything, providing an image for one's reference but with misrepresentation:

I often think looking at rankings or statistics was like looking into a distorting mirror - they will change your shape, making you look thinner or fatter. Images will appear differently on each distorting mirror, and we are looking at a different image of ourselves from what we truly are. However, since they are mirrors, we can at least have a rough idea of how we look. We can have a rough image, while realizing the image is twisted. ... We can choose to look at them, but do not regard them as the whole truth.

Some participants considered numbers to be relatively free from human intervention. They regarded the quantification in evaluations as an objective means 'in a nepotistic society (ren qing she hui, 人情社会) like China' (Academic-EB1, EB5, C5). 'Non-academic factors' were brought up by 30 interviewees as influential in Chinese academia, which included the interference of interpersonal relationship (guan xi, 关系; or ren qing, 人情), academic corruption or misconduct, administrative power, and the monopoly of established scholars or institutions.

An illustrative notion is '(academic) circle' (quan zi, 圈子; or xue shu quan, 学术 圈), mentioned by 35 academics and senior administrators. The term was sometimes used neutrally as a synonym to 'academia'. But several academics used its connotation, indicating the protectionism within certain 'circles' and the exclusivism for those outside the 'circles'. 'Circles' can be classified by location, discipline, language, research strands, or as some described that within Chinese academia, bonded with interpersonal relationship. Participants talked about 'international (academic) circle', 'SSCI circle', 'domestic (academic) circle', 'Chinese-speaking circle', 'our circle', and 'their circle'. All 'circles' appeared to be separated, hierarchical, and closed spaces where one is either an outsider or can 'enter' and 'be there' as an insider. Nobody talked about 'leaving' a circle, as if the status of being in a circle would be permanent. Several participants noted a 'small-circle-ism' (xiao quan zi zhu yi, 小圈子主义) in domestic academia, when close ties between circle members can circumvent academic integrity in publishing and evaluations, or when the circle leaders monopolize resources and pathways to academic development. Consequently, some expressed the view that to flourish in parts of the Chinese academia, one may need to be in the right 'circle'.

Under such circumstances, some participants believed that Chinese academia was not fair enough to rely solely on qualitative evaluation measures such as peer review, and that counting numbers is 'the best option before a healthy academic community is formed' (Academic-EA1). Academic-EA4, NB7, EB10, and administrator at Uni-C all associated such quantitative evaluation to the Chinese national college entrance exam, which relies heavily on test scores rather than on qualitative evaluation measures. They argued that although educational inequity was unavoidable, the exam was the most 'equal', 'objective', and 'manageable' system available for 
the selection of students; and by extension, so were evaluations of research based on quantity.

\section{Integrity and Instrumentalism}

A range of academic values were reported as being challenged or reinforced by institutional incentives. Particularly, academics depicted a strengthened notion of academic rigor, the perceived threats to their internal academic commitment, and a rise of instrumentalism.

Some academics reported an enhanced awareness of professionalism and rigor in academia, which they attributed to learning from foreign academics and journals through international exchanges, collaboration, and publications. For instance, many academics perceived international journals as having more rigorous peer review processes than domestic journals. Seven academics described their submission process to domestic journals with the same Chinese idiom, 'shi chen da hai' (石沉大海, translated as 'like a pebble dropped into the ocean'), meaning they had never heard anything back.

A group of academics expressed their intention to change the situation, by providing comprehensive, timely, and professional comments when serving as reviewers for domestic journals, and setting up rigorous peer review procedures when establishing or editing domestic journals. Some participants argued for building an 'academic community' (xue shu gong tong ti, 学术共同体), a notion developed from Polanyi's (1962: 57) 'scientific community'. In interviews, an 'academic community' was depicted as different from the 'small-circle-ism'; and as an open, equal, autonomous, and ethical space where every member follows academic ethics and professionalism. As Academic-EB12 noted, the improvement of academic rigor is not dependent on 'chanting slogans' or by administrative means; rather, 'it relies on the efforts and participation of each member in the academic community'. Several academics and editors reported that the standard of domestic research had indeed improved:

I believe, overall, the level of rigor is improving, particularly with more and more academics coming back... After seeing how things are done in a more standardized way, you will naturally try your best to do it that way, so the situation is improving. (Academic-EB12)

Nonetheless, academics interviewed demonstrated a common concern of instrumentalism shaped by the incentives. 15 interviewees used the term 'gong li' ( 功利) in discussions about research cultures, which can be translated literally as 'utility and efficacy' or 'fame and wealth'; and when used as an adjective, the synonym in English is 'utilitarian'. A related phrase 'ji gong jin li' (急功近利) was brought up by five participants, meaning 'seeking instant success and quick profits'. Six academics also used the phrase ‘tou ji’ (投机), meaning 'opportunism', to express their concerns about incentives' influences on research cultures.

'Fame and wealth', as perceived by some academics, already lurked in contemporary academia (Academic-C6). For example, Academic-W9 admitted that 
although academic interest was one of her biggest research motivations, she did not deny having secondary 'utilitarian' motivations, such as being promoted to a professorship. But, as Academic-C1 and Academic-EB1 commented, the financial incentives for publications in top journals were leading academics to chase utilitarian goals more directly. As Academic-EB5 remarked:

The problem is why policymakers would not simply provide more decent salaries for academics, for them to do research and teaching without further concerns. On the one hand, the wages are low; on the other hand, policymakers are using bait to lure academics. ... This system turns some academic researchers into 'academic laborers', as making money with papers is like the way laborers earn a living. ... Is academic work just a way of making a living? This is a horrible thing.

Some academics were concerned that the instrumentalism may impede the healthy development of HSS academia, resulting in people 'flooding' SSCI journals with low-quality submissions (Academic-C4, C12) or leading to plagiarism or faking research data as had been reported in NS (Academic-W2, NA4). Interviewees raised examples when what they called 'opportunists' benefited from 'playing the game'. For instance, the case of one 'SSCI professor' in HSS was mentioned as 'a big joke' by an interviewee. That 'SSCI professor' had published five SSCI papers within five years, and was consequently promoted to professor at 'the speed of a rocket'. However, all papers were published in one SSCI journal focusing on NS areas rather than the professor's own discipline, and s/he had not published anything in Chinese. Academic-W2 and EA8 raised similar examples.

Participants argued that the encouragement for short-term and instant outputs by incentive schemes contradicted the nature of HSS research, which required longterm preparation, immersion, and thinking. Academic-W2 commented that the environment of chasing instant benefits reflected 'an anxiety' in academia, which was a 'terrible thing':

This is an interesting academic ecology: what is awarded, and what you can produce to gain benefits - everything is totally legal, and through this process, I can get lots of money, lots of titles, and more money behind those titles. ... But research needs immersion and accumulation, not impetuosity. ... Such policies may work in the short-term. But if it continues, eventually, academics would not be incentivized to conduct in-depth and delicate research. For instance, if you spend lots of time writing something that may end up as 3,000 pages long, you cannot get the outcome immediately; neither would you be recognized soon. However, others may spend a few days writing a paper and get hundreds of thousands in bonuses. I think the latter would be a tremendous appeal to anyone.

Some academics perceived conflict between their internal commitment to research and external performative pressures. Interviewees reported various motivations to publish internationally beyond just financial or career related incentives, but also for self-development and actualization, intellectual communication, scholarly 
recognition, and societal impact. Academic-W9 and Academic-EA10 both underscored that academics should be guided by the intrinsic pursuit of truth and intellectual curiosity, rather than by external requirements or administrative forces, which would violate pure academic pursuits. Other participants agreed that the motivation of research should not be 'getting higher scores' (Academic-NA4) or 'making money' (Academic-NB1); if so, they had to 'fight with' their values and ideals (Academic-NB1, C1). Some argued 'the research will not be uncontaminated if you are aiming at incentives' (Academic-C13), which 'will betray the fundamental purpose of conducting research' (Academic-NA4, C10).

A few academics noted that one might need to strike a compromise between upholding academic values and being instrumental. Academic-EB7 observed that while some academics felt the conflicts, they had separated their academic job into two parts, one for fulfilling requirements and being instrumental, and the other for their academic interests and pursuits. As an illustrative example, Academic-EA1 perceived less external pressure as a professor, but he realized that his previous supervisee, a newly-employed assistant professor, was under circumstances where one may have to 'bow to reality' to live on. Because his supervisee has a high level of English proficiency, Academic-EA1 encouraged him/her to publish in English:

I told him/her, why not make use of the system? As long as you remain true to your original values, why not? Such systems could produce some opportunists, but so long as you do not become over-utilitarian in the future. You first try to adapt to it. You must pass the assessment, since there is no other way around. What else can we do?

Such statements echoed comments made by Academic-C12, who was an assistant professor:

I am treating it as a job now, not something else we used to think it was, especially how we thought it was when we were students. When you treat it as a job, you feel okay with many things. Just do a good job, and do not be too idealistic. After all, you have to consider the life of your partner and children.

Nonetheless, Academic-EA1 felt optimistic. He saw current measures as temporary, a phase that would end when sufficient numbers of academics reach the current requirement, thus prompting the university to raise its standards and 'eliminate those opportunists'.

\section{Equity and Inequity}

Academics presented various views on whether incentives had increased the level of equity or, to the contrary, had intensified inequities among scholars. Some academics considered the incentives and the consequent metric-based evaluations as relatively 'fair' and 'equal' criteria free from human interventions (Academic-NB7); as Academic-NA9 stated, 'to test whether you have done good research, just try to publish it in English'. 
However, a large number of interviewees perceived a direct or indirect contribution of incentives for international publications to reinforcing inequity in academia. They argued those who can publish internationally were like ‘feng mao lin jiao' (凤 毛麟角, a Chinese idiom used by Academic-C5, literally translated as 'phoenix's feather and unicorn's horn', meaning 'extremely rare and valuable'), so it is unequitable if only international publications were prioritized. It could create a win-lose situation as Academic-EB3 noted: 'The reward for some people is the deprivation of others'.

A commonly raised reason for inequity was the perceived 'yi dao qie' (一刀 切, literally translated as 'cutting everything with one stroke', meaning 'one size fits all') in policy-making and implementation. Nine interviews from different institutions and disciplines used this term to accuse institutions of judging academics from various backgrounds by a single standard. Academic-C1 noted that 'yi dao qie' policy did not 'respect the dignity of academics', since 'everyone has his/her own peculiarity, the policy should encourage everyone to bring the best out of oneself.' Academic-EB12 also remarked that 'yi dao qie' management 'is not respectful of the nature of academic research', which is 'definitely not delicate management'. Academic-W4 held that such policies tended to look for homogeneity, and as a result neglect the potential importance of heterogeneity in academic cultures.

Four groups of comparison emerged from interviews, which represent four facets of inequity as deemed most sensitive to the influences of incentive schemes. They are comparisons of academics from different universities, from different disciplines, between returnee and non-returnee academics, and between junior and senior academics.

\section{(1) Academics from different universities}

Many interviewees compared their own university to others, some of which were among the six case universities in this study. Participants often distinguished between NS-oriented universities and HSS-oriented universities. Academics from Uni-EA, Uni-NB, and Uni-W constantly mentioned that since their universities were traditionally NS-oriented, senior administrators were more science-minded and were more familiar with outputs in NS, resulting in the tendency to use quantitative metrics in institutional incentive policies.

Uni-EA and Uni-EB were brought up as a pair for comparison, with Uni-EA as more NS-oriented and Uni-EB more HSS-oriented. Participants reported that although Uni-EB incentivized HSS international publications, international publications were not a requisite for promotion or research evaluations like in some departments at Uni-EA. They perceived incentive policies at Uni-EB as not 'strict', 'intense' or 'imposing' (Academic-EB7, EB8, EB9), and considered the research environment as relatively 'relaxed' (Academic-EB1, EB5), 'free' (Academic-EB5, EB6, EB12), and 'humanistic'/ 'human-oriented' (yi ren wei ben, 以人为本) (Academic-EB8, EB12). Academic-EB1 concluded that Uni-EA appeared more like an 'industrial society' focusing on efficiency, while Uni-EB seemed like a leisurely 'agricultural society'. He thought although Uni-EB may be surpassed by Uni-EA on university rankings because of this 'leisurely' style, the flip side of it was a 
'better atmosphere and less pressure' (Academic-EA5), which was a research culture admired by a few interviewees from Uni-EA.

Participants used comparisons to suggest that their own university should offer more monetary bonuses for international publications, as they felt it was unfair to receive lower monetary rewards than their counterparts in other institutions. For instance, Academic-NA5 complained that another university awarded more than $¥ 30,000$ for SSCI publications, much more than that at Uni-NA. Academic-NB2 said that her SSCI publications could earn her $¥ 80,000$ or $¥ 30,000$ in some other universities, while it was only rewarded with $¥ 10,000$ at her university. Moreover, Academic-C4 pointed out that a top international publication could be worth $¥ 100,000$ at another university, but not at Uni-C. Academic-EB1, W5, and EB6 also noticed that some non- '985' or non- '211' universities implemented stronger incentives for international publications, due to a lack of such publications at those institutions.

\section{(2) Academics from different disciplines}

Participants drew comparisons between HSS and NS, arguing that NS subjects might be more suitable than HSS to become internationalized, and that publishing internationally was easier in NS than in HSS. Participants suggested that the language requirements for NS publications might be lower than that for HSS publications, as one can use equations and numeric data to express ideas in NS (Academic-EB7, C15), while 'HSS publications may require literary delicacy' (Academic-C5). Another reason raised was that NS dealt with 'universal' problems (Academic-NA3, W4, W8), while questions in HSS research were often rooted in the local context:

If I research cement, American academics can also examine the cement. However, Social Sciences research is about people, who are influenced by social structures, socio-economic development, and socio-cultural elements. Therefore, some disciplines can be internationalized, while others are difficult to become internationalized. (Academic-W8)

Academic-NA5 argued SCI papers were often shorter and with more standardized and replicable formats as compared to SSCI papers. A participant remarked that SCI journals outnumbered SSCI journals - with for instance, thousands of SCI journals in Computer Sciences, but only around ten in Translation. Academic-NB4, Academic-NA6, and Academic-W10 considered teamwork as useful to reduce preparation time for NS publications, while it was not the common working mode in every HSS discipline.

Participants acknowledged that HSS international publications were not as highly valued as NS publications according to the incentives. 12 academics noted publications in Nature and Science could bring millions of Chinese RMB in bonuses, far more than the bonuses for top publications in HSS. The differences extended beyond monetary value to institutional recognition and support. Both Academic-NB4 and NB5 talked about such differences perceived at their university, which were summarized in the comments by Academic-NB4: 
Since we all work at the same university, we will compare disciplines and departments. ... Our university is overly concerned about NS. For example, if someone published in Nature or Science, the university will hang banners on campus, and give them awards of $¥ 500,000$ or much more... Publishing an SSCI paper would not make the heart of our university leaders miss a beat, but a paper in Nature will. ... We do not expect to be as highly valued as NS, but it would be good if we have more space and platforms for development.

Academics suggested a differentiation in approaches to incentivizing and assessing HSS research. According to academics across disciplines (e.g. Academic-NA2 from French, Academic-EA4 from Media, and Academic-EB5 from Chinese), HSS research required a long period of accumulation, while NS research demanded fastpace innovation. As Academic-EA4 put it, 'a professor in HSS may not reach their peak in their 30s or 40s', but 'many professors in NS made their greatest achievements at younger ages'. Consequently, academics opposed incentives based on expecting a certain number of HSS publications per year, since they argued that an academic in HSS might need many years to produce a great piece of work. Interviewees like Academic-NA7 also thought monographs were often undervalued in incentives despite being essential to HSS research.

Within HSS disciplines, academics reported inequity among various subjects, since the blanket incentive scheme failed to address different levels of internationalization and publishing difficulties within HSS areas. As academics within or outside those fields observed, disciplines like Economics, Management, and Business tended to be at the higher end of the internationalization continuum, and publishing in international journals had already become a norm in those disciplines (noted by Academic-NA2, W4, EB4, NA7, C8, EA11, C12). A participant mentioned that their Department of Economics awarded SSCI publications with as high as $¥ 200,000$ bonuses, much higher than most university-level bonuses. In addition, academics from English disciplines were considered by some participants to be more capable of publishing internationally because of their language proficiency.

Inequity was perceived differently within each discipline and among academics focusing on different topic areas. For instance, Academic-EB11 from Chinese History confronted the idea that there might be a considerable gap between international and domestic research on Chinese History. Therefore, he thought it 'hilarious' in his discipline to 'think only internationalization could help us reach a good goal or foster academic development'. On the contrary, Academic-C14 from History observed that those researching World History might have certain advantages of perspectives for international publications. Similarly, Academic-EA9 suggested that scholars in Western Philosophy tended to be more internationalized than those in Chinese Philosophy.

\section{(3) Returnees and non-returnees}

Most participants considered returnee academics as having advantages over their non-returnee peers in international publications, thus benefiting more from incentive schemes. Some non-returnee academics expressed an inferior stance to returnee 
academics in interviews. For instance, returnees had a Chinese nickname as 'hai gui' (海归, literally translated as 'sea turtle'), as the homophone of 'return from overseas' in Chinese. The antonym coined for non-returnees was 'tu bie' (土鳖, literally translated as 'local softshell turtle') with a slight (self)sarcastic connotation. Five interviewees used 'tu bie' to describe non-returnees, among whom four referred to themselves. For instance, Academic-C12 said:

I am a tu bie - I studied all the way in China, so I started publishing with a focus on domestic journals. ... The recently reformed incentive policy is, as we tu bie see it, very striking. Returnees ... are bringing us huge impact.

Interviewees attributed returnee academics' advantages to their 'systematic research training abroad' (Academic-C14). Returnees were considered to be familiar with international research norms, publication formats, research questions, and academic English writing, as well as access to potential international networks and collaborators. Ten returnee academics confirmed publishing or planning to publish papers in English based on their master's or doctoral theses, which had been written in English and could be more easily converted into international publications. In comparison, a few participants like Academic-EA2 and Academic-W10 perceived doctoral training in China as inadequate. Returnee academics also reported international publications as a more convenient choice for them, due to the difficulties of publishing in Chinese. They reported challenges like switching academic languages and vocabularies, changing writing styles, catering for different academic cultures, and a lack of local support and networks in Chinese academia.

(4) Junior academics and senior academics

Some academics saw publishing internationally as a way for junior academics to escape from the perceived 'monopoly' of established academics in Chinese academia, thus creating a field for 'fair competition' (Academic-W2). For instance, Academic-C6 described five types of academics he observed in 'the ecology of Chinese academia': superstar academics, academic officials, academic teachers, academic researchers, and pure academics. He argued that the first two groups, who were often more senior, enjoyed more resources than others. Other participants also complained about the control of 'magnates' (da lao 大佬) (Academic-EA5, C5, NB5, EA8) or 'faction leaders' (shan tou 山头) (Academic-EA5, EA8) in their 'academic circles'. Participants noted that the concentration of resources and the consequent 'Matthew effect' (Academic-C5) associated with academic status and administrative power were reflected in domestic publications, research evaluations, grant applications, and career promotion (Academic-EA1, C5, EB5, EA7, EA8). Under such circumstances, Academic-NB5 remarked that there is limited space for a junior academic to break through domestically:

The monopoly in academic circles is fiercer than that in enterprises. Once a magnate becomes a renowned scholar, one will stay as a renowned scholar throughout their life. There is less and less space for junior academics. (Academic-NB5) 
Conversely, some interviewees argued that senior academics might be disadvantaged by current incentives. They commented that some established academics were not capable of publishing internationally, due to a lack of English proficiency and proper research training; while junior academics had better knowledge bases, academic vision, and the capability to communicate internationally (Academic-NB2, NA3). As the senior administrator at Uni-C explained, those senior academics who could not publish internationally were not the target group when they formulated incentive policies. Consequently, participants like Academic-W3 were concerned that such incentives could marginalize some senior academics, when they did not qualify for bonuses or further promotion due to the lack of international publications.

\section{Discussion}

The findings of this study point to a number of push and pull factors associated with incentive scheme policies, resulting in inclusion and exclusion concerns, equity and inequity issues, and rising apprehension over the impact on academic culture. These concerns give rise to the need for a wider discussion over the risk of managerialism and degradation of researcher agency in internationalized research cultures, especially in contexts where narrowly focussed incentive policies and evaluation schemes are pervasive.

\section{Managerialism and Academics' Agency}

The incentive schemes increased the institutional accountability of Chinese HSS academics, positioning them as 'managed professionals' (Blackmore 2003: 5) or as performative producers and consumers of publications. The emphasis of incentives on productivity and performativity shaped HSS academics' research and careers, just as Olssen (2016) argued, leading to some academics conforming to external regulations and motivations, some of which were at odds with aspects of their academic values.

The conflicts between upholding one's academic integrity and conforming to instrumentalism appeared as undesirable tensions rising from the current incentive systems, coupled with a utilitarian culture that favours instant benefits rather than long-term commitment. The conflicts between internal academic values and external incentive measures echo Cao's (2014: 155) comment on 'China's Nobel Prize Pursuit', that the top-down reward systems in China could be detrimental to core academic values that include 'truth-seeking, intellectual curiosity, challenging authority, and above all, freedom of inquiry'.

A managerial culture could also lead to the instrumental reification and alienation of academics (Lukács 1971; Marx 1964), making the value, process, and outcome of academic research externalised to researchers themselves. Under a blanket research policy, the value of academics could be simplified as equal to the number of their publications. Consequently, as Academic-EB8 commented, academics could become the 'hens' with their publications as 'eggs'. In his statement, hens lay 
eggs for the profit of the owners. The assumption is that academics do not truly own their publications and the publication itself does not matter, as publications will be translated into numbers for institutions (the perceived owner of academics and their academic outputs) to fulfil external evaluative goals like rankings. An alternative to the reifying culture is the 'humanistic' or 'human-oriented' (yi ren wei ben, 以 人为本) approach as perceived in case institutions like Uni-EB, where academics were not regarded as article-producing instruments that need to be managed, but respected as thinkers, researchers, scholars, or educators whose knowledge is intrinsically valuable.

Establishing a credible peer review system and a responsible academic community is a potential way to execute the collective agency of academics. But as the current study and existing literature revealed (e.g. Yang 2015; Cao 2014; Tenzin 2017), one major challenge exists. That is to uproot Chinese academia from a culturally nepotistic and administrative society, where academic ethics and quality can yield to non-academic factors and the power of 'circles'.

Nonetheless, this paper, alongside the findings presented in $\mathrm{Xu}$ (2020b), identified discourses and actions leading to transformation in Chinese academia. Academics demonstrated the intention and potential to build an autonomous academic community free of 'non-academic factors', and break through the protectionism and hierarchies of established 'circles'. This direction of change has been facilitated by recent national policies, which attempt to abolish the 'supremacy of SCI' (SCI zhi shang, SCI至上), and stress the need to establish a credible peer review system in research assessments (Ministry of Education 2020; Ministry of Education and Ministry of Science and Technology 2020). One document specifically urges peer reviewers to 'abide by academic ethics, provide responsible review comments' and follow the principle of avoidance in cases of conflict of interests (Ministry of Education and Ministry of Science and Technology 2020).

\section{One Size Does Not Fit All}

Academia is not a single entity without variation. However, the recent 'yi dao qie' (一刀切, one size fits all) incentive policies seem to suggest the opposite. Blanket research policies could lead to a homogenised academia where academics share similar targets narrowed down by evaluative mechanisms. They risk shrinking academics' epistemic, imaginative, and practical space, thus encouraging them to translate various kinds of academic, cultural, social, and economic capital (Bourdieu 1986) into one single entity quantified for research evaluation: publications in specific journals. Risky, creative, or non-conventional research that falls outside the evaluative target could be marginalized. The undesirable consequence, as Academic-C1 commented, would be that 'everyone is like a clone, and everyone is the same'.

The spotlight on publications could be detrimental to other activities such as teaching, as evidenced by the perceived devaluation of teaching by participants. Those findings confirm the points by Prendergast (1999: 8-9) that incentives on 
certain aspects of the work could lead to agents 'gaming' the compensation system, and reallocating activities towards directly compensated ones and away from uncompensated activities. It also corresponds to the comments by Hatch and Curry (2020: 2) from the DORA initiative that 'the over-reliance on proxy measures that tend to be focused on research can discourage researchers from working on other activities that are also important to the mission of most research institutions, such as teaching, mentoring, and work that has societal impact'.

The 'yi dao qie' incentive scheme may generate new-or cement pre-existinginequity in academia. Although some participants perceived incentive schemes as challenging entrenched hierarchies, such as between junior and senior academics, this potential is based on another form of inequity between the prioritized international publications and devalued indigenous research. While publishing internationally and 'going out' can bring Chinese indigenous knowledge to global academia and pluralize global sciences, as voiced by some interviewees and other scholars (Dang 2005; Deng 2010), there is a danger to indigenous knowledge if research evaluation regimes legitimatize 'western' theories, methods, and research questions. Incentives may also strengthen perceptions of an inferior status of HSS in comparison with NS research and insidiously generate further hierarchies within HSS research, since some disciplines and research areas were perceived as more conducive for international publication. In line with previous research, returnee academics expressed a willingness to publish internationally and perceived themselves as capable of producing international publications (e.g. Jonkers and Cruz-Castro 2013). Incentives could thereby reinforce returnee academics' privileges in academia.

\section{Conclusion}

This study revealed the influences of incentives for international publications on research cultures in Chinese HSS, demonstrated by tensions between internationalization and indigenization, quality and quantity, integrity and instrumentalism, equity and inequity. Considering these tensions, we propose several implications for institutional policymaking, which speaks not only to China but also to other systems with incentive mechanisms that aim to stimulate research productivity via an increase in publication volume (Franzoni et al. 2011).

In general, we suggest that one size does not fit all, and that research incentives and evaluation mechanisms should aim for approaches that support open, ethical, equitable, autonomous, and generous research cultures. We suggest universities enable 'human-oriented' rather than 'output-oriented' knowledge practices and research cultures, which can value and support academics as thinkers, researchers, scholars, educators, rather than managing them as merely producers of measurable research output. Despite structural constraints, academics have a certain level of agency to challenge prevailing research cultures. For that to happen, more academics could be engaged in decision-making and implementation of research evaluations. Finally, 
the evaluation of research should not be only based on publication counts and other narrow or wrongly extrapolated metrics, but evaluations should consider the intrinsic value, quality, originality, contribution, and impact of knowledge and research, in local, national, and international contexts.

Acknowledgements The authors would like to thank Professor Hubert Ertl for his invaluable support for the research, and the anonymous reviewers for the helpful feedback. Special thanks to all participants for generously sharing their insights.

Funding The research has been funded by the Economic and Social Research Council (Grant Number: ES/T006153/1); Clarendon Fund, University of Oxford; Universities' China Committee in London Research Grant; Santander Academic Travel Awards, University of Oxford.

Open Access This article is licensed under a Creative Commons Attribution 4.0 International License, which permits use, sharing, adaptation, distribution and reproduction in any medium or format, as long as you give appropriate credit to the original author(s) and the source, provide a link to the Creative Commons licence, and indicate if changes were made. The images or other third party material in this article are included in the article's Creative Commons licence, unless indicated otherwise in a credit line to the material. If material is not included in the article's Creative Commons licence and your intended use is not permitted by statutory regulation or exceeds the permitted use, you will need to obtain permission directly from the copyright holder. To view a copy of this licence, visit http://creativecommons.org/licen ses/by/4.0/.

\section{References}

American Society for Cell Biology. 2012. San Francisco Declaration on Research Assessment (DORA). Bethesda: American Society for Cell Biology.

Archambault, Éric, Étienne Vignola-Gagné, Grégoire Côté, Vincent Larivière, and Yves Gingras. 2006. Benchmarking scientific output in the social sciences and humanities: The limits of existing databases. Scientometrics 68: 329-342.

Blackmore, Jill. 2003. Tracking the nomadic life of the educational researcher: What future for feminist public intellectuals and the performative University? Australian Educational Researcher 30: 1-24.

Bourdieu, Pierre. 1986. The forms of capital. In Handbook of Theory and Research for the Sociology of Education, ed. J. Richardson, 241-258. New York: Greenwood.

Butler, Linda. 2003. Explaining Australia's increased share of ISI publications-The effects of a funding formula based on publication counts. Research Policy 32: 143-155.

Cao, Cong. 2014. The Universal Values of Science and China's Nobel Prize Pursuit. Minerva 52: $141-160$.

China Academic Degrees \& Graduate Education Information. 2009. 211 gongcheng jieshao [An introduction to "Project 211"].

China Academic Degrees \& Graduate Education Information. 2012. 985 gongcheng xuexiao mingdan [The list of "Project 985" universities].

Chou, Chuing Prudence. 2014. The SSCI Syndrome in Higher Education. A Local or Global Phenomenon. Rotterdam: Sense Publishers.

Dang, Shengcui. 2005. Can American standards set the highest evaluation benchmark for Chinese Social Sciences?-Take SSCI as an example [Meiguo biaozhun neng chengwei Zhongguo Renwensheke chengguo de zuigao biaozhun ma?_-Yi SSCI weili]. Social Sciences Forum 4: 62-72.

Deem, Rosemary, Sam Hillyard, and Mike Reed. 2007. Knowledge, higher education, and the new managerialism: The changing management of UK universities. Oxford University Press.

Deng, Zhenglai. 2010. Westernization of the Chinese Social Sciences: The case of legal science (19782008). In World Social Science Report 2010: Knowledge Divides, ed. UNESCO \& International Social Science Council, 182-183. Paris: UNESCO \& International Social Science Council.

Donovan, Claire. 2005. The governance of social science and everyday epistemology. Public Administration 83: 597-615. 
Fanghanel, Joelle. 2011. Being an academic. Abingdon, Oxon: Routledge.

Franceschet, Massimo, and Antonio Costantini. 2011. The first Italian research assessment exercise: A bibliometric perspective. Journal of Informetrics 5: 275-291. https://doi.org/10.1016/j.joi.2010.12. 002 .

Franzoni, Chiara, Giuseppe Scellato, and Paula Stephan. 2011. Changing incentives to publish. Science 333: 702-703.

Gao, Xuesong, and Yongyan Zheng. 2018. 'Heavy mountains' for Chinese humanities and social science academics in the quest for world-class universities. Compare: A Journal of Comparative and International Education 50: 1-19.

Garfield, Eugene. 2003. The meaning of the impact factor. International Journal of Clinical and Health Psychology 3: 363-369.

General Office of the CCP Central Committee, and General Office of the State Council. 2018. Opinions on deepening the reform of evaluating projects, academics, and institutions [Guanyu shenhua xiangmupingshen, rencaipingjia, jigoupinggu gaige de yijian].

Hatch, Anna, and Stephen Curry. 2020. Changing how we evaluate research is difficult, but not impossible. eLife 9: 1-8.

Hazelkorn, Ellen. 2011. Rankings and the Reshaping of Higher Education: The Battle for World-Class Excellence, 2nd ed. Basingstoke: Palgrave Macmillan. https://doi.org/10.1057/9780230306394.

Henkel, Mary. 2005. Academic identity and autonomy in a changing policy environment. Higher Education 49: 155-176.

Hicks, Diana, and Jian Wang. 2010. Towards a Bibliometric Database for the Social Sciences and Humanities-A European Scoping Project. Available at: http://works.bepress.com/diana_hicks/18/.

Huang, Mu Hsuan, and Yu Wei Chang. 2008. Characteristics of research output in social sciences and humanities: From a research evaluation perspective. Journal of the American Society for Information Science and Technology 59: 1819-1828. https://doi.org/10.1002/asi.20885.

Jiang, Chunlin. 2017. An analysis of China's SSCI publications and their impacts in the past ten years: Discussing the "Going-out" approach for humanities and social sciences outputs [Jinshinian woguo SSCI lunwen fawen he yingxiangli fenxi]. Journal of Southwest Minzu University (Humanities and Social Sciences): 224-234.

Jonkers, Koen, and Laura Cruz-Castro. 2013. Research upon return: The effect of international mobility on scientific ties, production and impact. Research Policy 42: 1366-1377.

Kelly, Aidan, and Roger Burrows. 2012. Measuring the value of Sociology? Some notes on performative metricisation in the contemporary academy. In Measure and Value, eds. Lisa Adkins and Celia Lury, 130-150.

Klein, Daniel B., and Eric Chiang. 2004. The Social Science Citation Index: A black box—with an ideological bias? Econ Journal Watch 1: 134-165.

Kolsaker, Ailsa. 2008. Academic professionalism in the managerialist era: A study of English universities. Studies in Higher Education 33: 513-525.

Li, Yunrong, Filippo Radicchi, Claudio Castellano, and Javier Ruiz-Castillo. 2013. Quantitative evaluation of alternative field normalization procedures. Journal of Informetrics 7: 746-755.

Lillis, Theresa, and Mary Jane Curry. 2010. Academic Writing in a Global Context: The Politics and Practices of Publishing in English. London: Routledge.

Liu, Weishu, Hu. Guangyuan, Li. Tang, and Yuandi Wang. 2015. China's global growth in social science research: Uncovering evidence from bibliometric analyses of SSCI publications (1978-2013). Journal of Informetrics 9: 555-569.

Lucas, Lisa. 2006. The Research Game in Academic Life. Maidenhead: Open University Press.

Lukács, Georg. 1971. History and Class Consciousness: Studies in Marxist Dialectics. London: Merlin Press.

Marx, Karl. 1964. Economic and philosophic manuscripts of 1844. New York: International Publishers.

Ministry of Education. 2011a. "Going-out" Strategy for Philosophy and Social Sciences in higher education institutions [Gaodengxuexiao zhexueshehuikexue "Zouchuqu" jihua].

Ministry of Education. 2011b. Opinions on further improvement of the evaluation of Philosophy and Social Sciences research in higher education institutions [Jiaoyubu guanyu jinyibu gaijin gaodengxuexiao zhexueshehuikexueyanjiu pingjia de yijian].

Ministry of Education. 2020. Opinions on eliminating the unhealthy 'paper-only' orientation in the evaluation of humanities and social sciences research in higher education institutions [Guanyu pochu gaoxiao zhexueshehuikexueyanjiu pingjia zhong 'wei lunwen' buliangdaoxiang de ruogan yijian]. http://www.moe.gov.cn/srcsite/A13/moe_2557/s3103/202012/t20201215_505588.html 
Ministry of Education, and Ministry of Science and Technology. 2020. Opinions on regulating the use of SCI indicators by higher education institutions and establishing the correct evaluation orientations [Guanyu guifan gaodengxuexiao SCI lunwen xiangguanzhibiao shiyong shuli zhengque pingjiadaoxiang de ruogan yijian].

Ministry of Education, Ministry of Finance, and National Development and Reform Commission. 2017. Releasing the lists of "world first-class universities" and "world first-class disciplines" [Jiaoyubu, Caizhengbu, Guojiafazhangaigewei guanyu gongbu shijieyiliudaxue he yiliuxuekejianshegaoxiao ji jianshexueke mingdan de tongzhi].

Ministry of Science and Technology. 2020. Measures to eliminate the unhealthy 'paper-only' orientation in the evaluation of science and technology (pilot) [Guanyu pochu keji pingjia zhong 'wei lunwen' buliang daoxiang de ruogan cuoshi (shixing)].

Moed, Henk F. 2010. Measuring contextual citation impact of scientific journals. Journal of Informetrics 4: 265-277.

Mongeon, Philippe, and Adèle Paul-Hus. 2016. The journal coverage of Web of Science and Scopus: a comparative analysis. Scientometrics 106: 213-228.

Montgomery, Catherine. 2011. Academic Research and Researchers Studies in Continuing Education, vol. 33. Maidenhead: Society for Research into Higher Education \& Open University Press.

National Education Committee. 1994. Opinions on the improvement of Humanities and Social Sciences research in higher education institutions [Guanyu jiaqiang he gaijin gaodengxuexiao renwenshehuikexueyanjiu gongzuo de ruogan yijian].

Nederhof, Anton J. 2006. Bibliometric monitoring of research performance in the social sciences and the humanities: A review. Scientometrics 66: 81-100.

Olssen, Mark. 2016. Neoliberal competition in higher education today: Research, accountability and impact. British Journal of Sociology of Education 37: 129-148.

Polanyi, Michael. 1962. The republic of science. Minerva 1: 54-73.

Prendergast, Canice. 1999. The provision of incentives in firms. Journal of Economic Literature 37: 7-63.

Qin, Hongxia, and Ruijing Zhang. 2008. Reflections on SSCI and academic evaluation of Humanities and Social Sciences in higher education institutions [SSCI yu gaoxiao renwenshehuikexue xueshupingjia zhi fansi]. Journal of Higher Education 3: 6-12.

Reale, Emanuela, Dragana Avramov, Kubra Canhial, Claire Donovan, Ramon Flecha, Poul Holm, Charles Larkin, et al. 2018. A review of literature on evaluating the scientific, social and political impact of social sciences and humanities research. Research Evaluation 27: 298-308.

Rietjens, Sebastiaan. 2015. Qualitative Data Analysis. In Routledge Handbook of Research Methods in Military Studies. Thousand Oaks, CA: Routledge.

Saldaña, Johnny. 2013. The Coding Manual for Qualitative Researcher (2nd Ed.), 3rd ed. London: SAGE Publications.

Scott, Peter. 2006. The academic profession in a knowledge society. In The Formative Years of Scholars, ed. Ulrich Teichler, 19-30. London: Portland Press.

Slaughter, Sheila, and Larry L. Leslie. 1997. Academic Capitalism: Politics, Policies, and The Entrepreneurial University. Baltimore: Johns Hopkins University Press.

Tenzin, Jinba. 2017. The Ecology of Chinese Academia: A Third-Eye Perspective. China Quarterly 231: $775-796$.

Trow, Martin. 1994. Managerialism and the Academic Profession: The Case of England. Higher Education Policy 7: 11-18.

US National Science Foundation. 2020. The state of U.S. science and engineering 2020.

Waltman, Ludo, Nees Jan van Eck, Thed N. van Leeuwen, and Martijn S. Visser. 2013. Some modifications to the SNIP journal impact indicator. Journal of Informetrics 7: 272-285.

Web of Science Group. 2020. Web of Science Core Collection: Social Sciences Citation Index (SSCI).

$\mathrm{Xu}$, Xin. 2019. Incentives for International Publications in the Humanities and Social Sciences: An Exploratory Study of Chinese Universities. Oxford: University of Oxford.

Xu, Xin. 2020a. China 'goes out' in a centre-periphery world: Incentivizing international publications in the humanities and social sciences. Higher Education 80: 157-172.

Xu, Xin. 2020b. Performing under 'the baton of administrative power'? Chinese academics' responses to incentives for international publications. Research Evaluation 29: 87-99.

Xu, Xin, Heath Rose, and Alis Oancea. 2019. Incentivising international publications: Institutional policymaking in Chinese higher education. Studies in Higher Education. https://doi.org/10.1080/03075 079.2019.1672646. 
Yang, Rui. 2014. China's strategy for the internationalization of higher education: An overview. Frontiers of Education in China 9: 151-162.

Yang, Rui. 2015. Reassessing China's higher education development: A focus on academic culture. Asia Pacific Education Review 16: 527-535. https://doi.org/10.1007/s12564-015-9397-2.

Zha, Qiang, and Wenqin Shen. 2018. The Paradox of Academic Freedom in the Chinese Context. History of Education Quarterly 58: 447-452.

Zhu, Jian. 2009. Academic evaluation, academic journals and academic internationalisation - Re-thinking on the fervour of Humanities and Social Sciences internationalisation [Xushupingjia, xueshuqikan yu xueshu guojihua: Dui renwenshehuikexue guojihuarechao de lengsikao]. Journal of Tsinghua University (Philosophy and Social Sciences) 5: 126-137.

Publisher's Note Springer Nature remains neutral with regard to jurisdictional claims in published maps and institutional affiliations. 